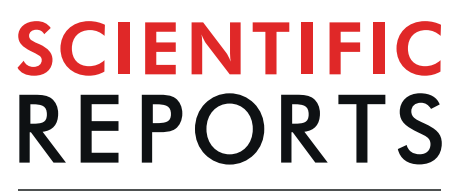

\title{
AT1 and AT2 receptors modulate renal tubular cell necroptosis in angiotensin II-infused renal injury mice
}

\author{
Yongjun Zhu ${ }^{1 *}$, Hongwang $\mathrm{Cui}^{2,4}$, Jie Lv ${ }^{3,4}$, Haiqin Liang ${ }^{1}$, Yanping Zheng ${ }^{1}$, Shanzhi Wang ${ }^{1}$, \\ Min Wang ${ }^{1}$, Huanan Wang ${ }^{1} \&$ Feng Ye $^{1^{*}}$
}

Abnormal renin-angiotensin system (RAS) activation plays a critical role in the initiation and progression of chronic kidney disease (CKD) by directly mediating renal tubular cell apoptosis. Our previous study showed that necroptosis may play a more important role than apoptosis in mediating renal tubular cell loss in chronic renal injury rats, but the mechanism involved remains unknown. Here, we investigate whether blocking the angiotensin II type 1 receptor (AT1R) and/or angiotensin Il type 2 receptor (AT2R) beneficially alleviates renal tubular cell necroptosis and chronic kidney injury. In an angiotensin II (Ang II)-induced renal injury mouse model, we found that blocking AT1R and AT2R effectively mitigates Ang II-induced increases in necroptotic tubular epithelial cell percentages, necroptosis-related RIP3 and MLKL protein expression, serum creatinine and blood urea nitrogen levels, and tubular damage scores. Furthermore, inhibition of AT1R and AT2R diminishes Ang II-induced necroptosis in HK-2 cells and the AT2 agonist CGP42112A increases the percentage of necroptotic HK-2 cells. In addition, the current study also demonstrates that Losartan and PD123319 effectively mitigated the Ang II-induced increases in Fas and FasL signaling molecule expression. Importantly, disruption of FasL significantly suppressed Ang II-induced increases in necroptotic HK-2 cell percentages, and necroptosis-related proteins. These results suggest that Fas and FasL, as subsequent signaling molecules of AT1R and AT2R, might involve in Ang II-induced necroptosis. Taken together, our results suggest that Ang II-induced necroptosis of renal tubular cell might be involved both AT1R and AT2R and the subsequent expression of Fas, FasL signaling. Thus, AT1R and AT2R might function as critical mediators.

Chronic kidney disease (CKD) is a significant global public health problem, and $14 \%$ of the US population and $10.8 \%$ of the Chinese population are affected by CKD. Notably, the incidence of CKD is increasing rapidly ${ }^{1-3}$. Much evidence supports the initial injury of renal tubular cells, with the activation of fibroblasts, and their replacement by extracellular matrix as significant factors responsible for the renal injury and remodeling found in $\mathrm{CKD}^{4}$. Despite the finding that necroptosis is a more important factor than apoptosis in mediating renal tubular cell injury and tubulointerstitial fibrosis in CKD in rats subjected to subtotal nephrectomy $(\mathrm{SNx})^{5}$, the specific mechanism of activation of this potential pathogenic pathway in renal tubular cells remains unclear.

It is well known that the renin-angiotensin system (RAS), including angiotensinogen, renin, angiotensinconverting enzyme, angiotensin II type 1 receptor (AT1R) and angiotensin II type 2 receptor (AT2R), is activated inappropriately in the diseased kidney during CKD progression. The inappropriate overactivation of the intrarenal RAS plays a critical role in renal tissue injury and remodeling in CKD progression via angiotensin II (Ang II) ${ }^{6,7}$. Importantly, once there is RAS overactivation leading to increased Ang II activity, an insidious stimulatory mechanism causing the sustained activation of the intratubular RAS develops, which can lead to the inappropriate activation of the intratubular RAS in the entire nephron population ${ }^{8}$, thus contributing to renal injury and $\mathrm{CKD}^{8-10}$.

${ }^{1}$ Department of Nephrology, The First Affiliated Hospital of Hainan Medical University, Hainan, China. ${ }^{2}$ Department of Orthopedics, The First Affiliated Hospital of Hainan Medical University, Hainan, China. ${ }^{3}$ The First Clinical College of Hainan Medical University, Hainan, China. ${ }^{4}$ These authors contributed equally: Hongwang Cui and Jie Lv. *email: zyj418207195@yeah.net; zcxy20080808@163.com 
Ang II mediates the majority of the classical biological functions of the RAS system and regulates renal cellular and physiological responses in the renal system. Ang II is also implicated in the pathophysiological processes related to renal fibrosis via activating renal tubular cells as well as local immune cells to increase cell apoptosis and the expression of pro-fibrotic factors (e.g., TGF- $\beta)^{11}$. Ang II signals through seven transmembrane-spanning G protein-coupled receptors that are characterized as AT1 or AT2 receptors based on their selective affinity for peptide and non-peptide ligands $\mathrm{s}^{12}$. AT1R and AT2R play an important role in cell growth, differentiation and apoptosis during development ${ }^{13-16}$. Abnormal AT1R and AT2R expression in the renal system has also been shown to be related to kidney diseases ${ }^{17,18}$. However, the detailed mechanism underlying Ang II-induced renal tubular cell necroptosis and kidney injuries is not fully understood. Therefore, we hypothesized that both AT1 and AT2 receptors might modulate Ang II-induced necroptosis of renal tubular cell. In the present study, we investigated whether blocking AT1R and/or AT2R signaling can beneficially alleviate renal tubular cell necroptosis in an Ang II-infused renal damage mouse model and in Ang II-induced HK-2 cells. Our results show that AT1R and AT2R signaling might be involved in Ang II induces a receptor-interacting serine-threonine kinase 3- (RIPK3) and mixed lineage kinase domain-like (MLKL)-dependent form of regulated cell death (necroptosis) in vitro and in vivo, and these data provide novel information for the study of AT1R- and AT2R-mediated mechanisms in renal tubular cell loss and renal tubulointerstitial fibrosis.

\section{Materials and Methods}

In vivo model of Ang II-induced renal injury. The animal care and use of this study were approved by the Ethics Committee of Hainan Medical University, and the methods were carried out in accordance with the approved guidelines. Male C57BL/6 mice (8-10 weeks old) were purchased from Beijing Vital River Laboratory Animal Technology Co., Ltd. The animals were housed at an optimal temperature with a 12:12 h light-dark cycle and free access to food and water in the Hainan Research Center for drug safety evaluation.

Thirty male mice were divided randomly into five groups ( $n=6$ per group): an Ang II group, which received continuous Ang II infusion ( $1.5 \mu \mathrm{g} / \mathrm{kg} / \mathrm{min}$, Sigma) dissolved in 10\% DMSO via a subcutaneous osmotic mini-pump (Alzet) after uninephrectomy surgery and was administered $0.9 \%$ sterile saline orally; Ang II + Nec-1 or losartan or PD123319 treatment groups, which received continuous Ang II infusion $(1.5 \mu \mathrm{g} / \mathrm{kg} / \mathrm{min}$, Sigma) via a subcutaneous osmotic mini-pump (Alzet) after uninephrectomy surgery and were administered Nec-1 $(1.65 \mathrm{mg} / \mathrm{kg} / \text { day })^{19,20}$ (Sigma-Aldrich, USA) or losartan $(10 \mathrm{mg} / \mathrm{kg} / \text { day })^{21}$ (MedChem Express, USA) or PD123319 $(10 \mathrm{mg} / \mathrm{kg} / \text { day })^{22}$ (Cayman Chemical, USA) dissolved in $10 \%$ DMSO via intraperitoneal injection; and a control group, which was subjected to only uninephrectomy surgery and was administered $0.9 \%$ sterile saline orally. All animals were euthanized at 21 days after treatment. At this endpoint, blood samples were collected for renal function analysis. The animals were perfused with PBS, and the kidney tissues were retrieved for protein isolation and for histological analysis.

Cell culture and stimulation. The HK-2 human renal proximal tubular epithelial cell line was purchased from ATCC (Manassas, VA, USA). The cells were cultured in DMEM/F12 medium (Gibco Life Technologies, Carlsbad, CA, USA) containing 10\% FBS (HyClone, USA) and 1\% penicillin and streptomycin (Beyotime, Shanghai, China) in a humidified incubator with $5 \% \mathrm{CO} 2$ at $37^{\circ} \mathrm{C}$. After reaching $80 \%$ confluence, the cells were starved in serum-free medium for $24 \mathrm{~h}$ before the experiment.

Next, the cells were stimulated with Ang II at a concentration range of $10^{-10}-10^{-5} \mathrm{M}$ for $24 \mathrm{~h}$. To elucidate the relevant mechanisms, the cells were pretreated with an AT1R antagonist $\left(10 \mu \mathrm{M}\right.$ losartan $\left.{ }^{23,24}\right)$ and an AT2R antagonist $\left(10 \mu \mathrm{M}\right.$ PD12331923,24) for $30 \mathrm{~min}$ or a RIP1 inhibitor $\left(50 \mu \mathrm{M} \mathrm{Nec}-1^{25}\right)$ for $30 \mathrm{~min}$ or a FasL inhibitor $\left(3 \mu \mathrm{g} / \mathrm{ml}^{26,27}\right.$ neutralizing human Fas ligand/TNFSF6 antibody (RD Systems, USA)) for $2 \mathrm{~h}$. After pretreatment for the indicated durations, HK-2 cells were exposed to $10^{-9} \mathrm{M}$ Ang II for $24 \mathrm{~h}$. The HK-2 cells were exposed to $10^{-9} \mathrm{M}$ Ang II for $24 \mathrm{~h}$ treated cells were collected at the indicated times for transmission electron microscopy (TEM), immunofluorescence staining, and Western blot analysis.

Histopathologic and renal function analyses. A portion of the retrieved mouse kidney tissue was fixed in $4 \%$ buffered formaldehyde and embedded in paraffin. After deparaffinization and rehydration, 4-micrometer-thick sections were subjected to hematoxylin and eosin (H\&E) staining. The staining results were analyzed under a bright field microscope. For quantitative analysis, at least 10 random high-power fields (400X) were selected, and the tubular damage scores were evaluated using a microscope as described by Garber et al. ${ }^{28}$.

Blood urea nitrogen and serum creatinine levels were measured using standard clinical biochemical techniques for assessing renal function in mice.

Flow cytometric analysis. Flow cytometric analysis was performed using a FITC annexin V apoptosis detection kit (BD Biosciences, San Diego, CA) according to the manufacturer's protocol. Briefly, cells were seeded into 6-well plates at a density of $5 \times 10^{5}$ cells/well and exposed to Ang II at different concentrations for 24 hours. Then, the cells were harvested, washed twice with precooled PBS and resuspended in $100 \mu$ of binding buffer. After the addition of $5 \mu \mathrm{l}$ of FITC annexin V and PI, the cells were incubated for $15 \mathrm{~min}$ at room temperature in the dark, and the samples were diluted with $400 \mu$ of binding buffer. Afterward, necrotic cells were distinguished by a flow cytometer (BD Biosciences, San Jose, CA). The percentages of the cells residing in the upper right (necrotic cells, annexin $\mathrm{V}^{+} / \mathrm{PI}^{+}$) regions of the annexin $\mathrm{V}$-FITC scatter plots were calculated.

Western blotting analysis. Western blotting assays were carried out as previously described ${ }^{29,30}$. Briefly, tissue samples or cell lysates were prepared in ice-cold radioimmunoprecipitation assay (RIPA) buffer (Beyotime, Nantong, Jiangsu, China). Equal amounts of total protein were subjected to SDS-PAGE and transferred onto PVDF membranes, which were blocked and incubated overnight with the following primary antibodies: anti-RIP3 monoclonal antibody (\#95702, Cell Signaling Technologies) or anti-RIP3 polyclonal antibody (ab152130, 
Abcam, Cambridge, MA, USA), anti-phospho-RIP3 monoclonal antibody (ab205421, Abcam, Cambridge, MA, USA), anti-MLKL polyclonal antibody (\#28640, Cell Signaling Technologies) or anti-MLKL monoclonal antibody (\#14993, Cell Signaling Technologies), anti-phospho-MLKL monoclonal antibody (ab208910, Abcam, Cambridge, MA, USA) or anti-phospho-MLKL monoclonal antibody (\#91689, Cell Signaling Technologies), or anti- $\beta$-actin monoclonal antibody (sc-47778, Santa Cruz Biotechnology, CA, USA). After washing, the membranes were incubated with the appropriate secondary antibodies conjugated with horseradish peroxidase (HRP). Immune-reactive signals were visualized by an enhanced chemiluminescence (ECL) kit (Millipore, USA) on a Syngene PXi6 Access imaging system (Frederick, MD). The band intensities were quantified using Image-Pro Plus 6.0.

TEM. Kidney tissue and cells treated with the reagents described previously were harvested; $1-\mathrm{mm}^{3}$ renal tissue fragments and centrifuged cells were fixed in $4 \%$ glutaraldehyde phosphate buffer $(\mathrm{pH} 7.4)$ overnight at $4{ }^{\circ} \mathrm{C}$, rinsed with PBS and postfixed in $2 \%$ osmium tetroxide. Then, the fixed renal tissue fragments and cells were dehydrated in an ascending series of ethanol and embedded in epoxy resin. Finally, ultrathin sections (60-70 nm) were stained with uranyl acetate and alkaline lead citrate, and the ultrastructure of the cells was visualized under a transmission electron microscope (Hitachi-7700, Japan).

Immunofluorescence detection of RIP-3 and in situ fluorescent TUNEL staining. Sagittal kidney tissue sections (4- $\mu$ m-thick) and HK-2 cells seeded on chamber slides (Thermo Scientific, USA) and incubated with the previously described treatments were prepared for RIP3 immunofluorescence staining and in situ fluorescent TUNEL staining. First, the sections and cells were fixed with $4 \%$ paraformaldehyde (Sigma-Aldrich, USA), followed by permeabilization in $0.1 \%$ Triton X-100 and incubation with 5\% BSA (Sigma-Aldrich, USA). The slides and cells were incubated with an anti-RIP3 monoclonal antibody (\#95702, Cell Signaling Technologies, Danvers, MA, USA) or anti-RIP3 polyclonal antibody (ab152130, Abcam, Cambridge, MA, USA) overnight at $4{ }^{\circ} \mathrm{C}$ and then with Alexa Fluor 594-conjugated goat anti-rabbit IgG $(\mathrm{H}+\mathrm{L})$ (\#4413, Cell Signaling Technologies). After rinsing 3 times with $0.1 \mathrm{M}$ PBS (pH 7.4), the samples were incubated with in situ cell death detection kit reagents (Fluorescein, Roche, Basel, Switzerland) according to the manufacturer's instructions and counterstained with 4',6-diamidino-2-phenylindole (DAPI). Finally, the images were captured by confocal microscopy (LEICA TCS SP2, Wetzlar, Germany), and cell counting was performed by a pathologist blinded to the experimental conditions.

Statistical analysis. The data are presented as the means \pm SEM. Multiple group comparisons were performed by one-way ANOVA followed by the Bonferroni procedure for the comparison of means. $\mathrm{p}<0.05$ was considered statistically significant.

\section{Results}

Inhibition of AT1R and AT2R suppresses renal tubular epithelial cell necroptosis in Ang II-treated renal injury mice. We explored whether blocking AT1R and AT2R would affect renal tubular epithelial cell necrosis using TEM. Figure 1A shows the microstructural changes observed in renal tubular epithelial cells under TEM. In the Ang II + vehicle group, many renal tubular epithelial cells showed a necrotic morphology, with markedly swollen cells, membranolysis and organelle contents disappearance and extensive intracellular vacuole formation. These findings are consistent with the typical morphological features of necroptotic cell death ${ }^{20,31}$. In addition, apoptotic renal tubular epithelial cells were occasionally observed in kidneys derived from Ang II- infused renal injury mice. However, the integrity of renal tubular epithelial cells were preserved in the Ang II + Nec-1 treated mice, and the percentage of necrotic renal tubular epithelial cells in the Ang $\mathrm{II}+\mathrm{Nec}-1$ treated mice was lower than that in the Ang II + vehicle group $(\mathrm{p}<0.01)$ (Fig. 1A,C). Importantly, we observed that the addition of losartan or PD123319 also preserved the integrity of renal tubular epithelial cells $(p<0.01)$ (Fig. 1A,C), which was similar to the effects of Nec-1 ( $>0.05)$ (Fig. 1A,C).

To confirm that the necrotic renal tubular epithelial cells under TEM were necroptotic cells, we performed RIP3 immunofluorescence staining and in situ fluorescent TUNEL staining. Rasl-Kraupp B et al. and other researchers reported that necrosis can also generate DNA fragments that react with the TUNEL reaction solution $^{31,32}$. Therefore, TUNEL staining and RIP3 immunofluorescence staining are used to determine the type of cell death that a cell undergoes. Cells that were positive for TUNEL staining and positive for RIP3 were considered to be necroptotic cells in this study. As shown in Fig. 1B,D, we found that Ang II treatment significantly increased TUNEL-positive and RIP3-positive expression in tubular epithelial cells compared with the control treatment $(\mathrm{p}<0.01)$. However, this TUNEL-positive and RIP3-positive expression was significantly subdued in the Nec1 -treated mice with chronic Ang II infusion $(p<0.01$ ) (Fig. 1B,D), further suggesting that necroptosis is involved in renal tubular epithelial cell necrosis. Importantly, we also found that losartan- or PD123319-treated mice had significantly lower percentages of TUNEL-positive and RIP3-positive tubular epithelial cells in their kidney tissues than Ang II-infused mice $(\mathrm{p}<0.01)$ (Fig. 1B,D). These data suggest that blocking AT1R with losartan and AT2R with PD123319 might supressed renal tubular epithelial cell necroptosis in chronic Ang II-infused mice.

Inhibition of AT1R and AT2R diminishes necroptosis-related proteins in Ang II-induced renal injury mice. RIP3, MLKL and their phosphorylated proteins are the key proteins of the necroptosis pathway, and their expression levels have been shown to correlate closely with necroptosis ${ }^{33}$. RIP3 is activated by binding and interacting with RIP1, and activated RIP3 recruits and subsequently phosphorylates downstream signaling molecule MLKL (on Ser345/Ser347 in mouse MLKL). MLKL phosphorylation is believed to trigger a molecular switch for programmed cell death, and result in necroptosis ${ }^{34}$. Therefore, we assessed RIP3, MLKL and their phosphorylated proteins expression in kidney tissues from Ang II-infused mice using Western blotting. 
Ang II
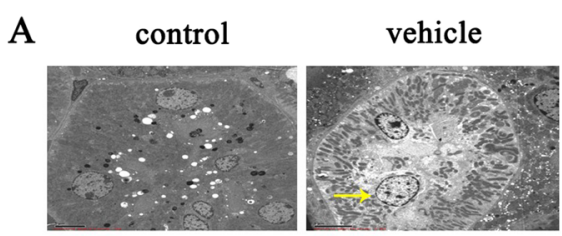

$$
\text { PD123319 }
$$
losartan

Nec-1
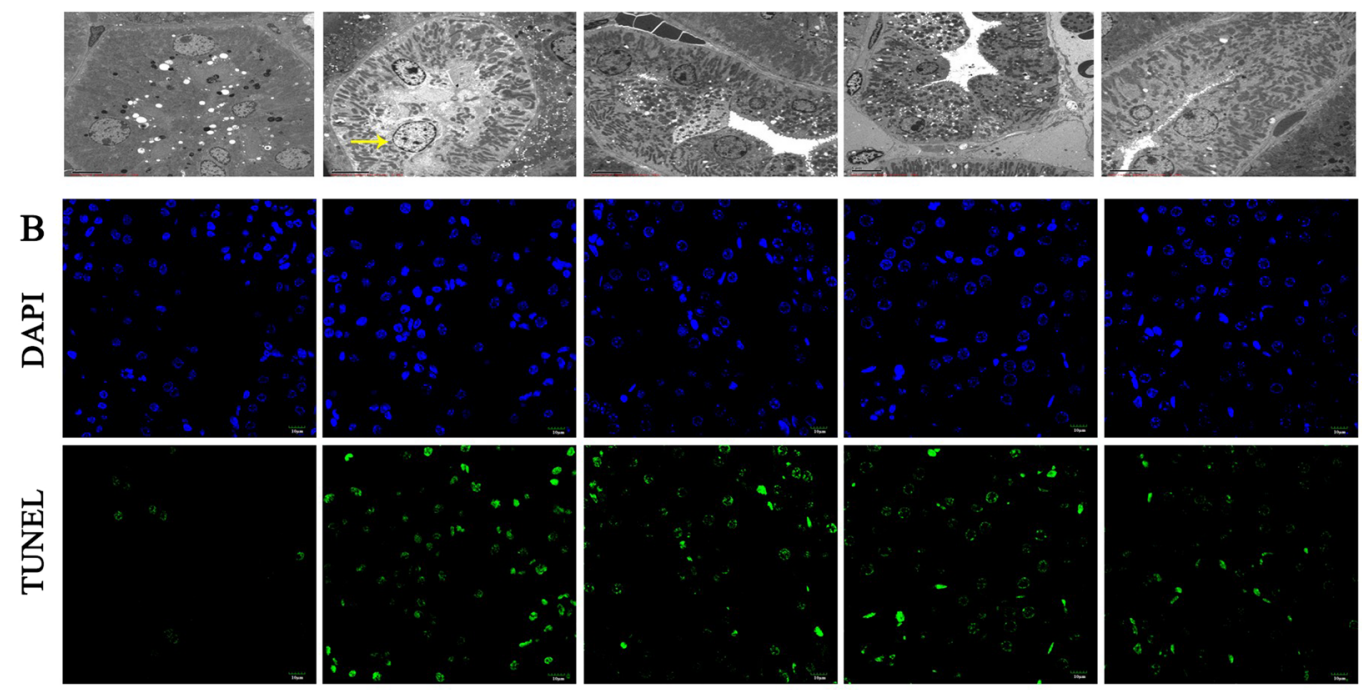

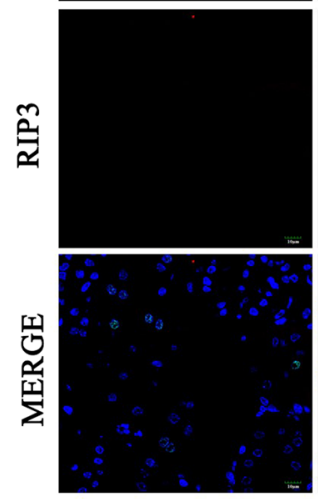

C

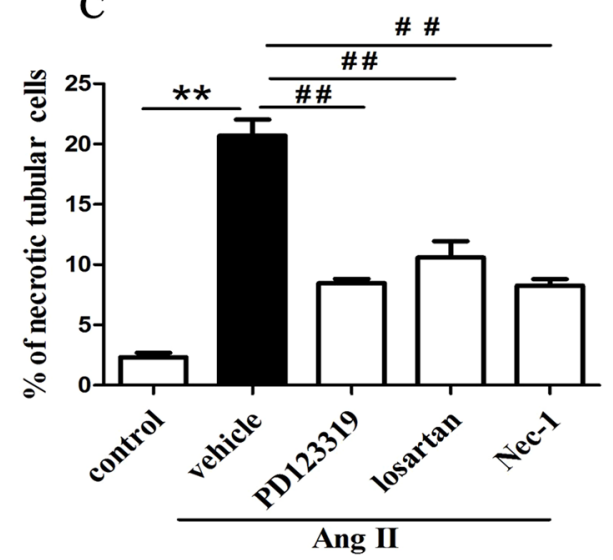

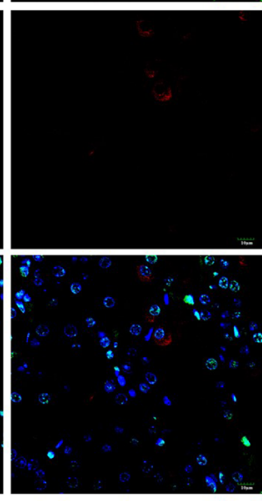
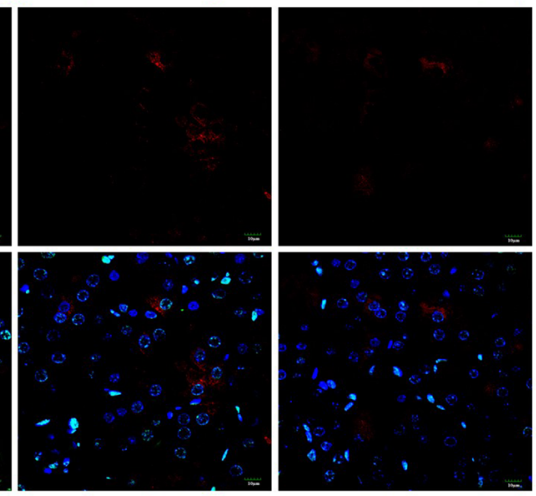

D

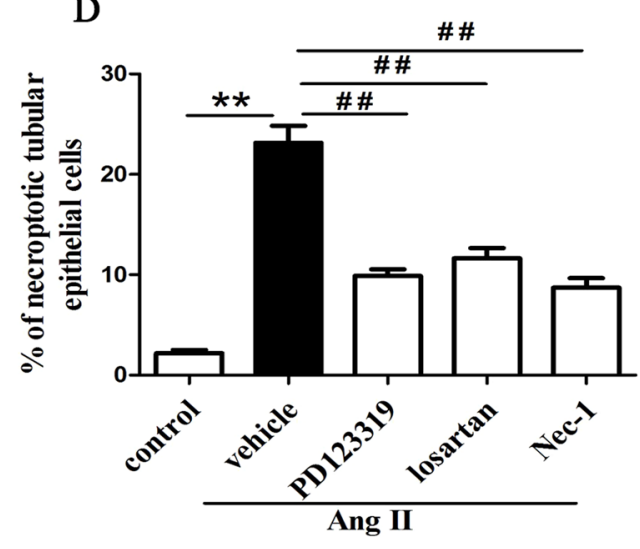

Figure 1. Inhibition of AT1R and AT2R suppresses renal tubular epithelial cell necroptosis in Ang II-treated renal injury mice. (A) Representative TEM images of necrotic tubular epithelial cells (as shown by the arrow) in the kidney tissues of Ang II-treated mice. (B) TUNEL-stained (green fluorescence) cells in the mouse renal tubules were costained to detect RIP3 (red fluorescence) and the nuclei (DAPI, blue fluorescence). The scale bars represent $10 \mu \mathrm{m}$. (C) The \% ratio of necrotic tubular epithelial cells (as shown by the arrow) was analyzed. (D) The data are presented as the \% ratio of TUNEL-positive and RIP3-positive tubular cells (necroptotic tubular cells). For the data in $(\mathbf{C}, \mathbf{D})$, the values are reported as the means \pm S.E.M. of $n=6 ; * * p<0.01$, versus control; ${ }^{\#} \mathrm{p}<0.05,{ }^{\# \#} \mathrm{p}<0.01$, versus the Ang II-treated group. Ang II: angiotensin II.

The Western blotting results revealed that Ang II treatment significantly up-regulated the protein expression of the necroptotic cell markers RIP3, p-RIP3 and MLKL, p-MLKL (p < 0.01) (Fig. 2A-E). However, blocking AT1R activity with losartan or inhibiting AT2R activity with PD123319 effectively suppressed the Ang 
A

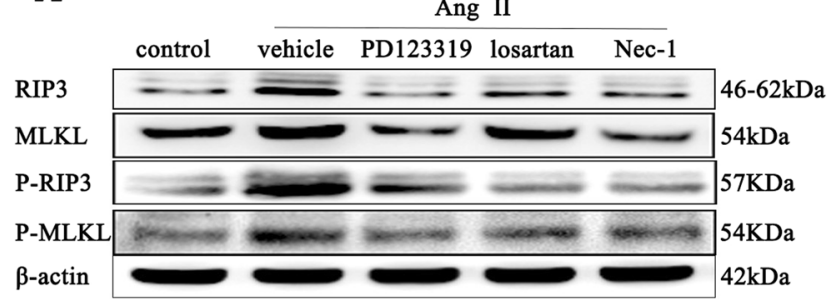

C

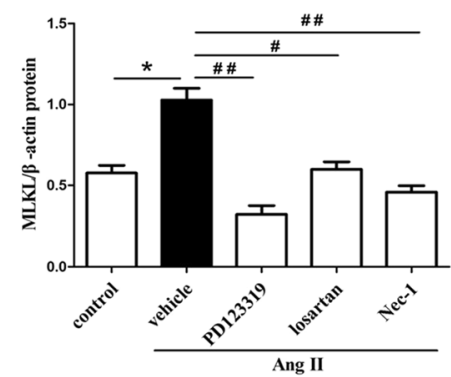

F

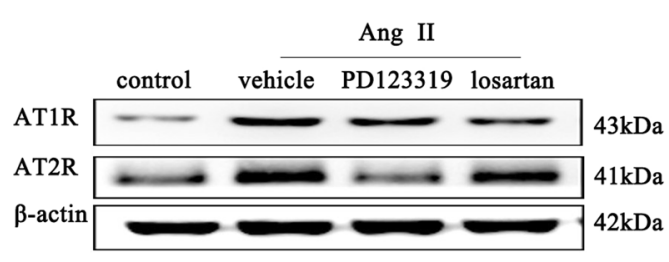

D

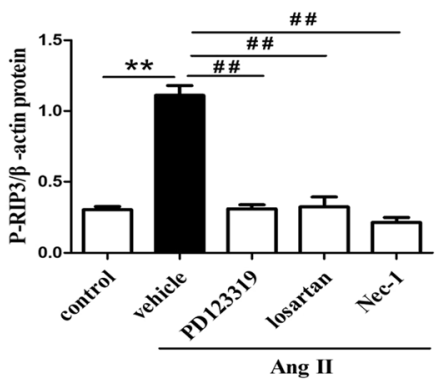

G

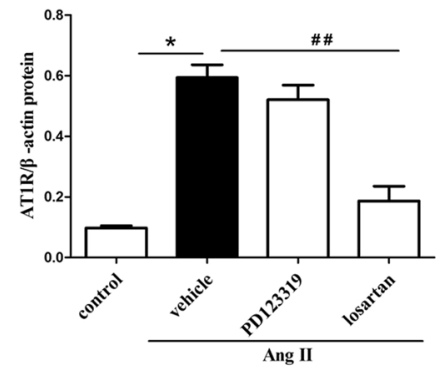

B

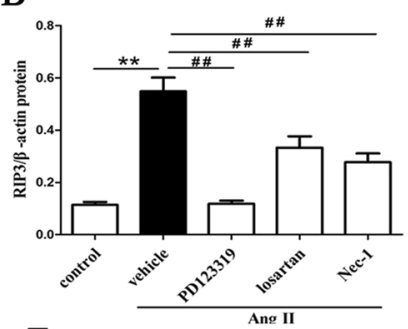

$\mathrm{E}$

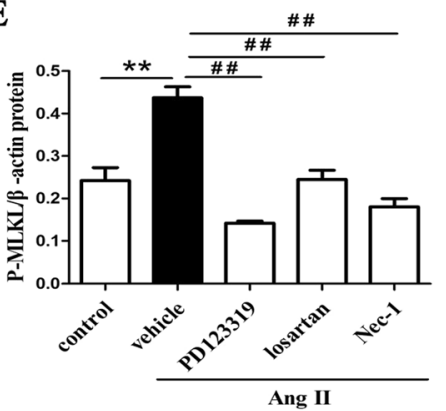

$\mathrm{H}$

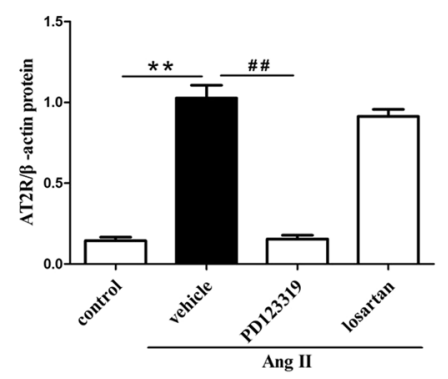

Figure 2. Inhibition of AT1R and AT2R diminishes necroptosis-related proteins in Ang II-induced renal injury mice. Tissue lysates of the retrieved mouse kidneys were subjected to SDS-PAGE and Western blotting with RIP3, p-RIP3, MLKL and p-MLKL (A), AT1R and AT2R (F) antibodies and a $\beta$-actin antibody. The intensities of the bands were determined quantitatively using Image-Pro Plus $6.0(\mathbf{B}-\mathbf{E}, \mathbf{G}, \mathbf{H})$. For the data in $(\mathbf{B}-\mathbf{E}, \mathbf{G}, \mathbf{H})$, the values are reported as the means \pm S.E.M. of $n=6$; ${ }^{*} \mathrm{p}<0.05$ and $* * \mathrm{p}<0.01$, versus control; ${ }^{*} \mathrm{p}<0.05$, $\# \mathrm{p}<0.01$, versus the Ang II-treated group. Ang II: angiotensin II.

II-induced expression of these proteins $(\mathrm{p}<0.01)$ (Fig. 2A-E), which was similar to the effects of Nec-1 $(\mathrm{p}>0.05)$ (Fig. 2A-E).

In addition, the expression levels of AT1R and AT2R were significantly higher in kidney tissues from Ang II-infused mice than from the control group $(\mathrm{p}<0.01)$ (Fig. $2 \mathrm{~F}-\mathrm{H})$. Losartan reduced the protein expression of AT1R $(p<0.01)$ but had no effect on AT2R $(p>0.05)$. PD123319 also diminished AT2R levels but did not change AT1R levels $(\mathrm{p}>0.05)$.

These results suggest that AT1R and AT2R might respectively modulate the RIPK3-MLKL-mediated necroptosis induced by Ang II in Ang II-infused mice.

Inhibition of Necroptosis improves renal function and renal injury in a mouse model of Ang II-induced renal injury. We next examined the histopathologic features of kidney tissues from Ang II-induced renal injury mice to determine the effect of necroptosis on renal pathologic structure. H\&E staining revealed that tubular injury scores were significantly higher in the Ang II-infused group than in the control group $(\mathrm{p}<0.01)$ (Fig. 3A,B). However, this renal injury response was significantly attenuated in the Nec-1-treated, PD123319-treated and losartan-treated mice with chronic Ang II infusion ( $\mathrm{p}<0.01)$ (Fig. 3A,B).

We also examined serum creatinine and blood urea nitrogen levels as markers of renal function. As shown in Fig. 3C,D, serum creatinine and blood urea nitrogen levels were significantly higher in the Ang II-infused group than in the control group $(\mathrm{p}<0.01)$. However, the Ang II-induced increases in serum creatinine and blood urea nitrogen levels were significantly mitigated by Nec-1, losartan and PD123319. In addition, we found that Ang II infusion increased systolic blood pressure in AngII-treated mice $(\mathrm{p}<0.01)$. Blocking AT1R with losartan significantly mitigated increased blood pressure, but Nec-1 and PD123319 had no remarkable effect on the increased blood pressure of the AngII-infused mice (Fig. 3E). The data suggested that ANG II-induced necroptosis might be involved both AT1 and AT2 receptors, and blockade of both may beneficially alleviate renal tubular epithelial cells necroptosis and renal tubule injury in Ang II-induced renal injury mice. 


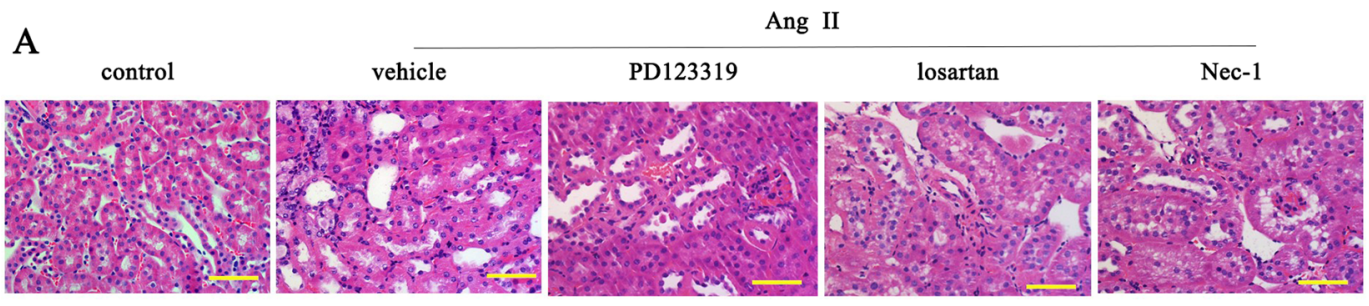

B

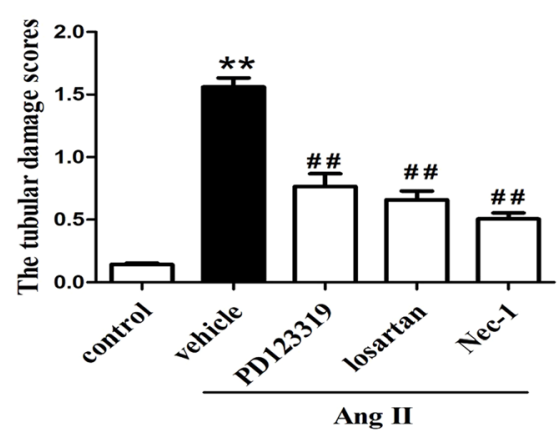

$\mathrm{D}$

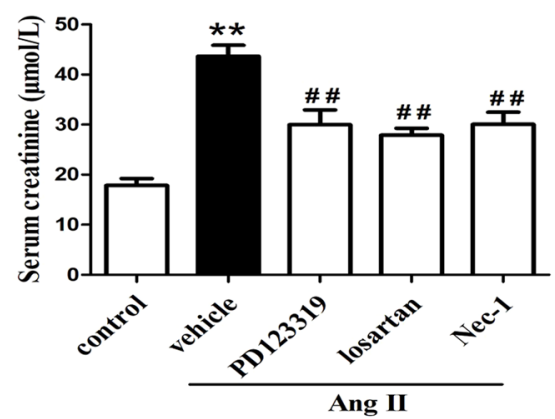

$\mathrm{C}$

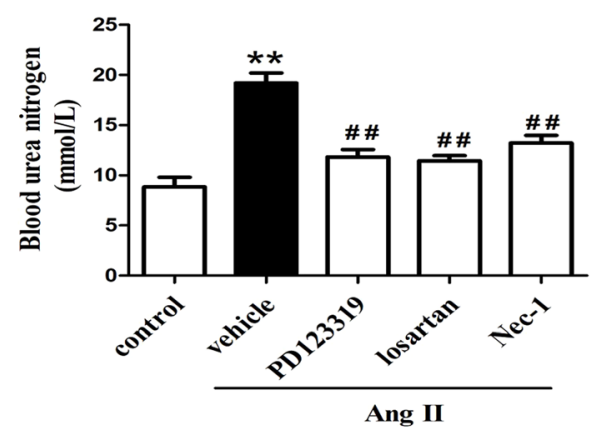

$\mathrm{E}$

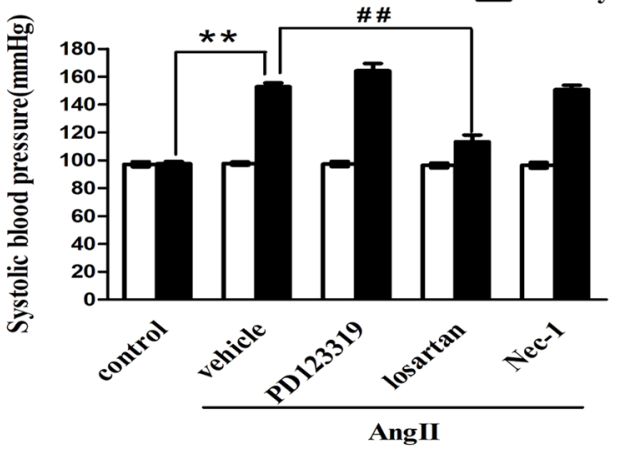

Figure 3. Necroptosis inhibition improves renal function and renal injury in a mouse model of Ang II-induced renal injury. (A) H\&E staining of the kidney tissues retrieved from Ang II-infused mice treated with or without PD123319 or losartan or Nec-1 ( $\mathrm{n}=6$ per group). Representative images are shown. (B) The tubular damage scores were assessed using a light microscope. Ang II-induced increases in blood urea nitrogen (C) and serum creatinine (D) levels were significantly reversed by PD123319 or losartan or Nec-1. (E) The systolic blood pressure was assessed. ${ }^{* *} \mathrm{p}<0.01$ versus control; ${ }^{* \#} \mathrm{p}<0.01$ versus the Ang II-treated group. Ang II: angiotensin II.

Ang II induces RIPK3-MLKL-mediated necroptosis in HK-2 cells. HK-2 cells were subjected to different concentrations of Ang II $\left(10^{-5}-10^{-10} \mathrm{M}\right)$ for $24 \mathrm{~h}$. When the Ang II concentration was $10^{-8} \mathrm{M}$, the ratio of annexin $\mathrm{V}^{+} / \mathrm{PI}^{+}$cells was remarkably increased $(\mathrm{p}<0.01$, Fig. $4 \mathrm{~A}, \mathrm{~B})$, and the ratio of annexin $\mathrm{V}^{+} / \mathrm{PI}^{+}$cells was highest in the HK-2 cells treated with $10^{-9} \mathrm{M}$ Ang II ( $\mathrm{p}<0.01$, Fig. $\left.4 \mathrm{~A}, \mathrm{~B}\right)$. In addition, cells were pretreated with $10^{-9} \mathrm{M}$ Ang II for various times $(0,12,24,48,36$, and $72 \mathrm{~h})$, and remarkable increases in the annexin $\mathrm{V}^{+} / \mathrm{PI}^{+}$cell ratio were observed after $24 \mathrm{~h}$ of Ang II stimulation ( $\mathrm{p}<0.01$, Fig. 4C,D). Taken together, these data indicated that Ang II induces necrosis in HK-2 cells in a dose- and time-dependent manner, and $10^{-9} \mathrm{M}$ and $24 \mathrm{~h}$ were selected as the Ang II stimulation conditions for the subsequent experiments.

To test whether Ang II-induced necrosis in HK-2 cells might be RIPK3 -MLKL-mediated necroptosis, we also investigated the effects of Ang II on key necroptosis proteins (RIP3, MLKL, P-RIP3, and P-MLKL) using Western blotting (Fig. 5). Compared with cells stimulated with PBS alone, HK-2 cells stimulated with Ang II had significantly higher expression levels of RIP3, MLKL, p-RIP3 and p-MLKL ( $<<0.01)$ (Fig. 5A-E), and these changes were blocked effectively by Nec-1, PD123319 and losartan ( $p<0.01$ ). Interestingly, a quantitative analysis confirmed that the RIP3, MLKL, p-RIP3 and p-MLKL protein levels were similar among the three pretreatment groups ( $p>0.05$ ). Collectively, these results suggest that RIPK3-MLKL-mediated necroptosis may be at least in part responsible for Ang II-induced necrosis in HK-2 cells, and both AT1 and AT2 exert important effect on necroptosis of Ang II-induced HK-2 cells.

Inhibition of AT1R and AT2R diminishes Ang II-induced necroptosis in HK-2 cells. HK-2 cells were cultured in vitro and analyzed with fluorescent TUNEL staining and RIP3 immunostaining assays to further investigate the role of AT1R and AT2R in Ang II-induced HK-2 cell death (Fig. 6A). The quantitative analysis of fluorescent TUNEL staining and RIP3 immunostaining revealed that the necroptotic incidence was higher 
A

HK2 Control

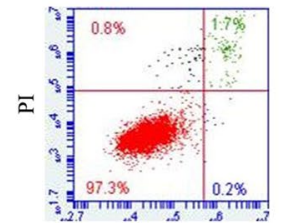

Annexin V-FITC $10^{-7} \mathrm{M}$ Ang II $24 \mathrm{~h}$

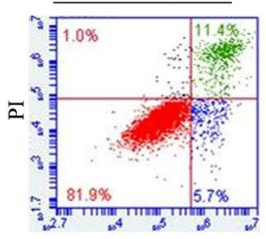

Annexin V-FITC $10^{-10} \mathrm{M}$ Ang II $24 \mathrm{~h}$

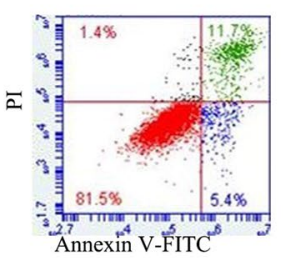

$10^{-5}$ M Ang II $24 \mathrm{~h}$

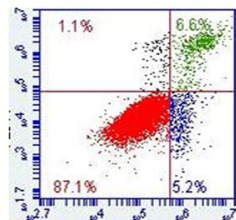

$10^{-8} \mathrm{M}$ Ang II $24 \mathrm{~h}$
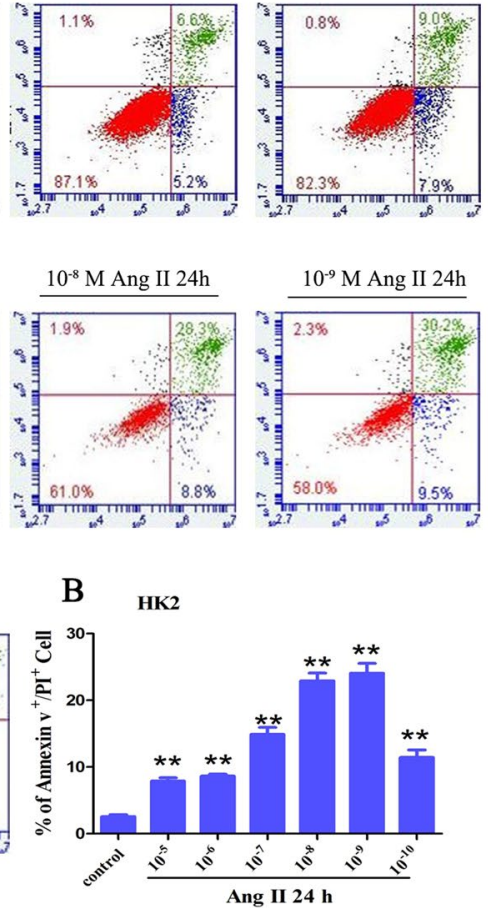

$\mathrm{C}$

HK2

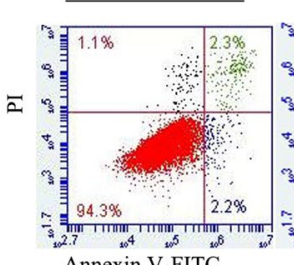

$10^{-9} \mathrm{M}$ Ang II $12 \mathrm{~h}$

$10^{-9} \mathrm{M}$ Ang II $24 \mathrm{~h}$
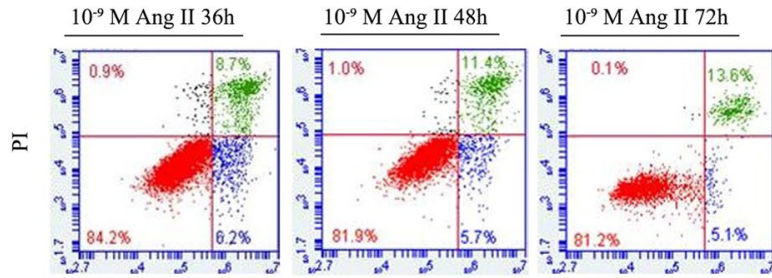

Annexin V-FITC

D HK2

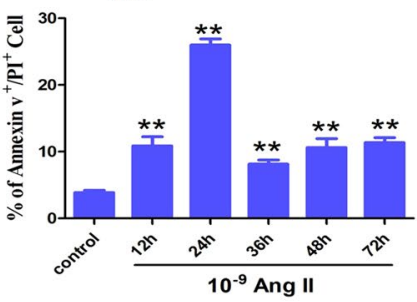

Figure 4. Detection of necrotic tubular epithelial cells using a flow cytometer. (A,B) HK-2 cells were treated with varying concentrations of Ang II $\left(10^{-10}-10^{-5} \mathrm{M}\right)$ for $24 \mathrm{~h}$. (C,D) HK-2 cells were exposed to $10^{-9} \mathrm{M}$ Ang II for different times. After treatment, HK-2 (upper panel) cells were stained with annexin V-FITC and PI to determine cell necrosis (annexin $\mathrm{V}^{+} / \mathrm{PI}^{+}$cells) using a flow cytometry assay. The bar chart shows that the ratio of annexin $\mathrm{V}^{+} / \mathrm{PI}^{+}$cell numbers was highest in the HK-2 cells treated with $10^{-9} \mathrm{M}$ Ang II for $24 \mathrm{~h}$.

in HK-2 cells treated with Ang II than in cells stimulated with PBS alone ( $<<0.01$, Fig. 6A,C), whereas the cells treated with PD123319, losartan or Nec-1 had a significantly lower necroptotic incidence than cells treated with Ang II ( $\mathrm{p}<0.01$, Fig. 6A,C).

TEM was used to observe the ultrastructure of HK-2 cells stimulated with Ang II to better understand their morphological characteristics. The TEM results demonstrated that all of the HK-2 cells stimulated with Ang II displayed a necrotic morphology (Fig. 6B). More importantly, cotreatment with Ang II and losartan or PD123319 greatly reduced the necrotic incidence of HK-2 cells (Fig. 6B,D), which was similar to the decreased necrotic incidence of HK-2 cells treated with Nec-1 ( $\mathrm{p}>0.05)$. These results were consistent with those of the fluorescent TUNEL staining and RIP3 immunostaining assays.

To prove AT2R might function as critical mediators in necroptosis of renal tubular cell, HK-2 cells were treated with the AT2 agonist CGP42112A (MedChemExpress, America) at different concentrations $(0,0.1,1$, and $10 \mu \mathrm{mol} / \mathrm{L}$ ) for 24 hour. In qPCR and Western Blot analysis, the level of RIP3 and MLKL mRNA and protein was at the highest when the cells were treated with $1 \mu \mathrm{mol} / \mathrm{L}$ CGP42112A (Fig. 7A-E). It is more important that we found CGP42112A $(1 \mu \mathrm{mol} / \mathrm{L})$ significantly increased the percentage of necroptotic HK-2 cells $(\mathrm{p}<0.01)$ (Fig. 7F-G) with fluorescent TUNEL staining and RIP3 immunostaining assays, which was blocked by PD123319 or Nec-1. In addition, we investigated the effects of CGP42112A on RIP3, MLKL, P-RIP3, and P-MLKL using Western blotting, and found that stimulation with CGP42112A increased significantly levels of RIP3, MLKL, p-RIP3 and p-MLKL protein in HK-2 cells $(\mathrm{p}<0.01)($ Fig. $7 \mathrm{H}, \mathrm{I})$, and the increase was blocked effectively by PD123319 and Nec-1 (p $<0.01)$.

Inhibition of AT1R and AT2R mitigates the expression of Fas/FasL signaling molecules in Ang II-induced HK-2 cells. Fas and FasL protein expression was detected in Ang II-stimulated HK-2 cells by Western blotting. Fas and FasL expression levels were significantly higher in HK-2 cells stimulated with Ang II than in cells stimulated with PBS alone ( $\mathrm{p}<0.01$, Fig. 8A,D,E). Losartan and PD123319 effectively mitigated the Ang II-induced increases in Fas and FasL signaling molecule expression $(p<0.01)$. Importantly, disruption of FasL significantly suppressed the necroptotic incidence $(\mathrm{p}<0.01$, Fig. $8 \mathrm{C}, \mathrm{J})$ and necroptosis-related proteins, including RIP3, MLKL, P-RIP3 and P-MLKL and FasL expression ( $\mathrm{p}<0.01$, Fig. 8B,F-I). These results suggest that AT1R and AT2R and the subsequent Fas/FasL signaling might be involved in Ang II-induced necroptosis. 
A
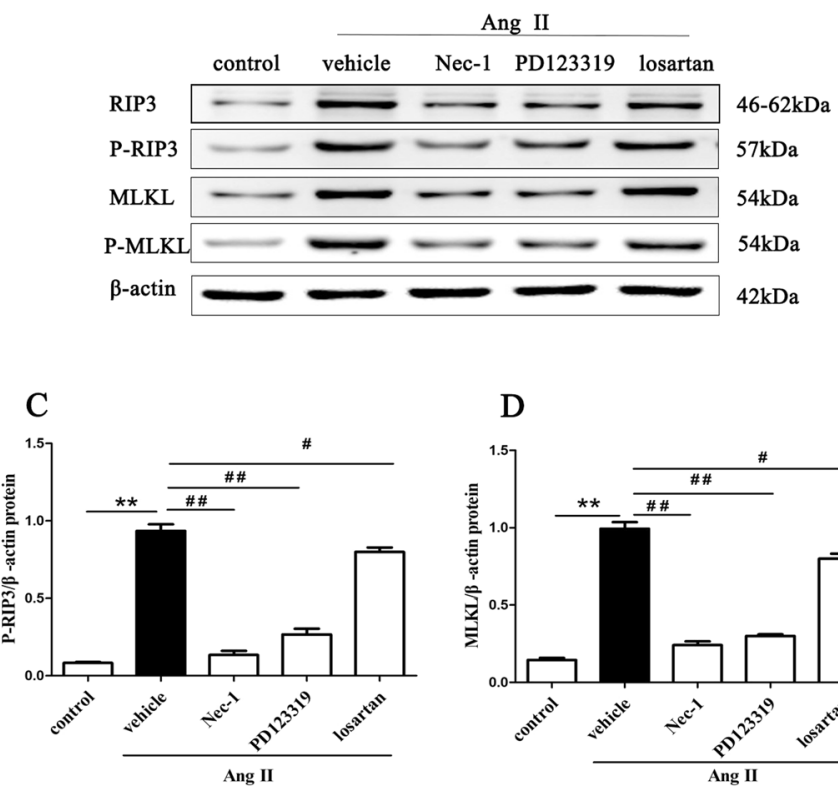

D

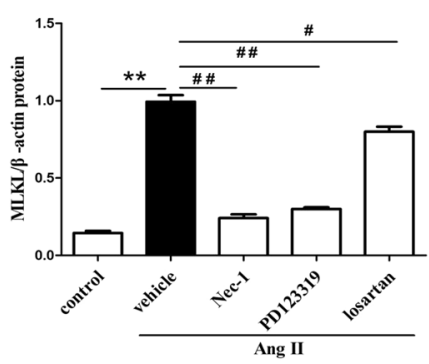

B

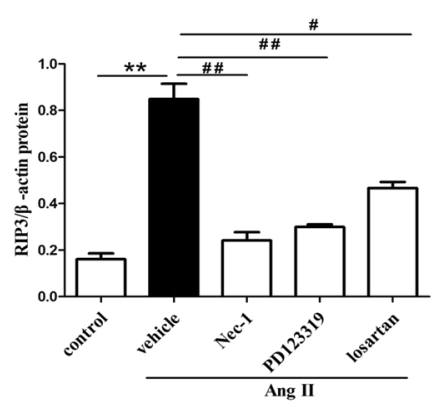

$\mathrm{E}$

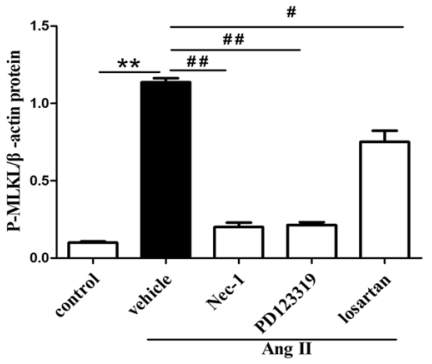

Figure 5. Ang II induces RIPK3-MLKL-mediated necroptosis in HK-2 cells. HK-2 cells were pretreated with or without $10 \mu \mathrm{M}$ losartan and $10 \mu \mathrm{M}$ PD123319 for $30 \mathrm{~min}$ or $50 \mu \mathrm{M} \mathrm{Nec}-1$ for $30 \mathrm{~min}$, followed by exposure to $10^{-9} \mathrm{M}$ Ang II for $24 \mathrm{~h}$. Representative Representative blots (A) and Western blot analysis (B-E) for necroptosis marker proteins: RIP3, MLKL, p-RIP3, and p-MLKL antibodies were used; $\beta$-actin was used as a loading control. The results are representative of three independent experiments. The intensities of the bands were determined quantitatively using Image-Pro Plus $6.0{ }^{* *} \mathrm{p}<0.01$ versus control; ${ }^{*} \mathrm{p}<0.05$, ${ }^{* *} \mathrm{p}<0.01$ versus the Ang II-induced group. Ang II: angiotensin II.

\section{Discussion}

The abnormal activation of Ang II plays a central role in the initiation and progression of $\mathrm{CKD}^{35-38}$, and the renoprotective effects of inhibiting its receptors are well known. It has been increasingly recognized that in addition to its hemodynamic effects, Ang II can exert direct effects on kidney cells ${ }^{38-41}$. Our current study revealed a novel paradigm for explaining the mechanisms of action of Ang II. We selected an Ang II infusion mouse model, wherein we provided a constant supply of Ang II to the tissue with an osmotic pump. The model used in the present study allowed us to determine the direct effect of Ang II on renal tubular cells without involving the role of ACE in Ang II production. We used TEM and confocal microscopy to find that Ang II effectively increased the percentage of necroptotic tubular epithelial cells compared with apoptosis in Ang II-infused renal injury mice and in Ang II-stimulated HK-2 cells. In accordance with these findings, the protein expression levels of the necroptotic cell markers RIP3, MLKL, p-RIP3 and p-MLKL were significantly increased by Ang II treatment in vivo and in vitro. These results were notably different from those of previous reports showing that Ang II can induce apoptosis in renal proximal tubular cells via both AT1R and AT2 $\mathrm{R}^{42}$, suggesting that Ang II signals can have detrimental effects on renal tubular cells via necroptosis pathway.

Classically, the majority of biological actions of Ang II are mediated by its cognate AT1 G protein-coupled receptor. AT1R has been implicated in a variety of pathologic conditions, such as hypertension, chronic heart failure and diabetic nephropathy. In addition, AT1R has been implicated in a variety of pathologic conditions, such as hypertension, cell growth, differentiation during development ${ }^{13-16}$ and apoptosis in renal proximal tubular cells. In the present study, we investigated the effects of AT1R on Ang II-induced necroptosis in renal tubular cells. The results showed that Ang II treatment significantly upregulated the expression of AT1R. Importantly, antagonists of AT1R activity, such as losartan, could effectively suppress the percentage of necroptotic renal tubular epithelial cells and the expression of necroptosis-related proteins in vivo in vitro. Therefore, we speculate that AT1R signaling might be mediated partly Ang II-induced renal tubular cell necroptosis.

AT2R plays an important role in cell growth, differentiation and apoptosis during development ${ }^{14,15}$, but the pathophysiological role of AT2R in CKD has not been defined clearly ${ }^{43-45}$. A previous study showed that there was reciprocal expression between AT1R and AT2R in response to Ang II infusion, with evident AT1R upregulation and AT2R downregulation ${ }^{46,47}$. However, the current data clearly challenge that concept. At least in kidney tissue, Ang II-treated adult mice exhibited higher AT2R protein levels with increasing AT1R levels. Importantly, functionally antagonizing AT2R activity with PD123319 could effectively diminish renal tubular epithelial cell necroptosis induced by Ang II cytotoxicity. Furthermore, we found that CGP42112A (an AT2 agonist) significantly increased the level of RIP3 and MLKL in HK-2 cells and the percentage of necroptotic HK-2 cells, which was blocked by PD123319 or Nec-1. These results suggest that both AT1 and AT2 receptors might be involved in 


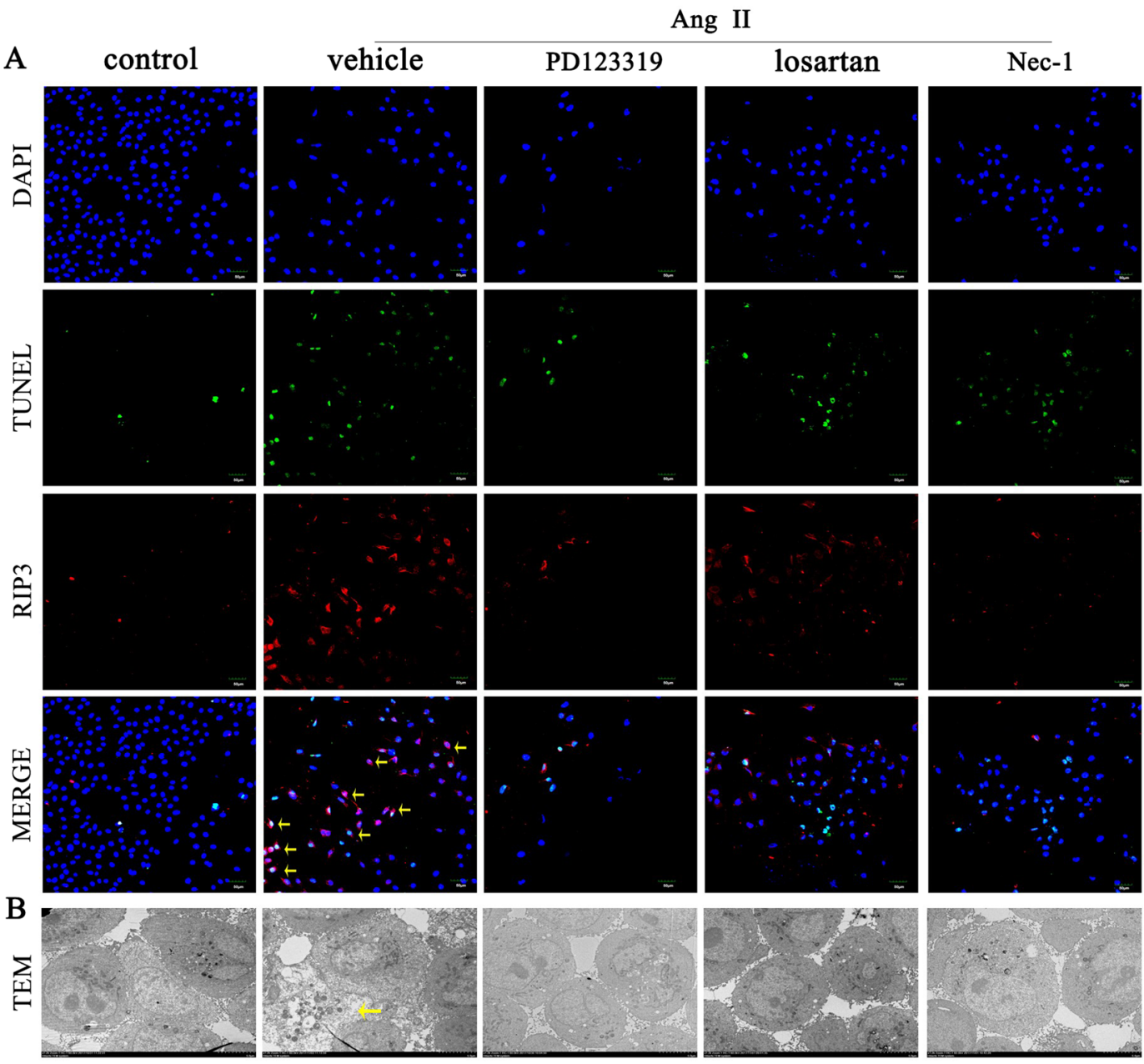

$\mathrm{C}$

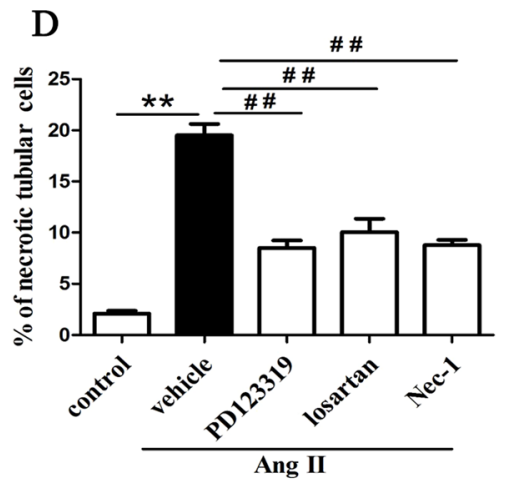

Figure 6. Inhibition of AT1R and AT2R diminishes Ang II-induced necroptotic HK-2 cells. (A) TUNELstained (green fluorescence) HK-2 cells treated with $10^{-9} \mathrm{M}$ Ang II for $24 \mathrm{~h}$ were costained to detect RIP3 (red fluorescence) and the nuclei (DAPI, blue fluorescence). The scale bars represent $50 \mu \mathrm{m}$. (B) Representative TEM images of necroptotic HK-2 cells (as shown by the arrow) after treatment with $10^{-9} \mathrm{M}$ Ang II for $24 \mathrm{~h}$. The scale bars represent $5 \mu \mathrm{m}$. (C) The data are presented as the \% ratio of necroptotic HK-2 cells(as shown by the arrow). (D) The data are presented as the \% ratio of necrotic cells among all HK-2 cells treated with $10^{-9} \mathrm{M}$ Ang II for $24 \mathrm{~h}$. For the data in $(\mathbf{C}, \mathbf{D})$, the values are reported as the means \pm S.E.M. of $n=6$; $* * p<0.01$, versus control; ${ }^{\#} \mathrm{p}<0.01$, versus the Ang II-treated group. Ang II: angiotensin II.

Ang II-induced necroptosis of renal tubular cell, which is similar to Ang II-induced apoptosis occurring via both AT1R and AT2R ${ }^{42}$.

Lastly, our results indicate that blocking AT1R and AT2R signaling effectively diminishes the expression of the death receptors Fas and FasL in the kidney. Fas and its ligand (FasL) are members of the tumor necrosis factor receptor superfamily and induce a series of intracellular signaling events, culminating in the activation of death-inducing signaling complexes, which promote apoptosis ${ }^{42,48}$. In this study, we also observed that blocking 
A

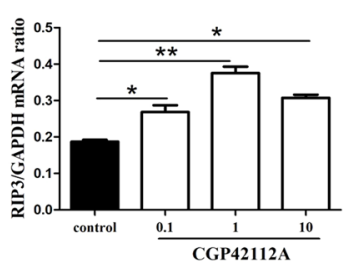

F

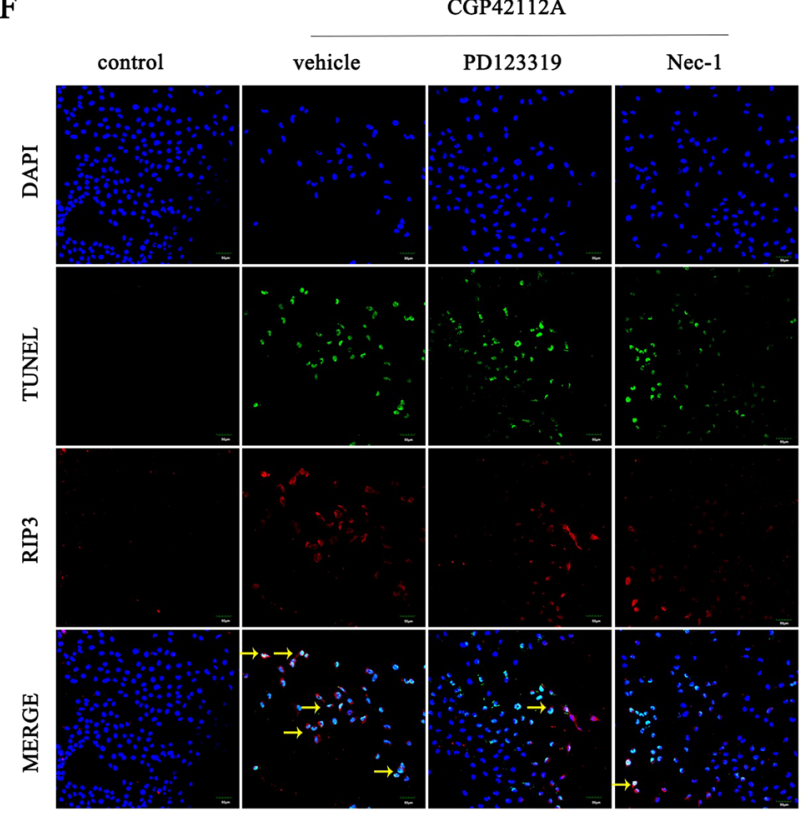

$\mathrm{H}$

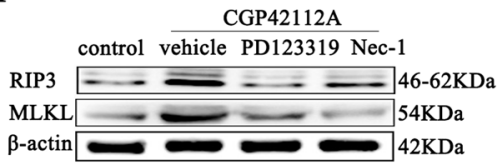

I

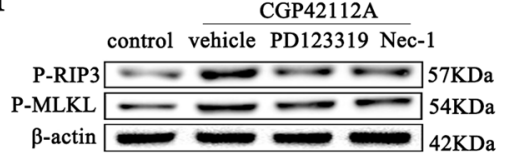

B

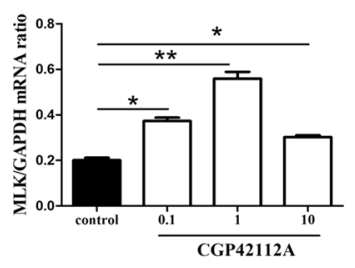

CGP42112A
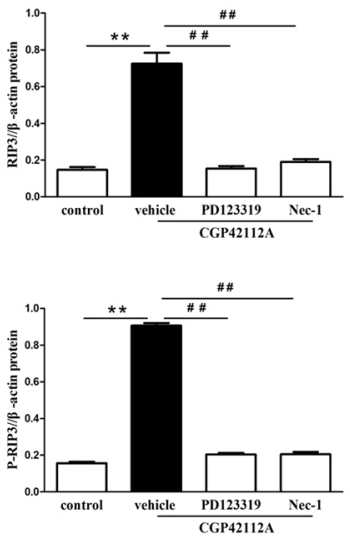

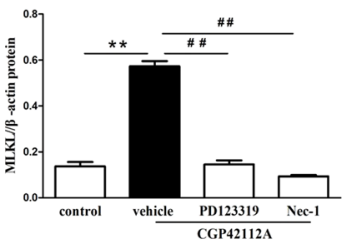

$\mathrm{C}$

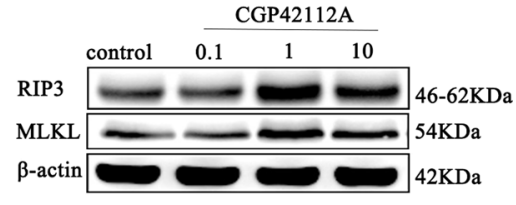

D

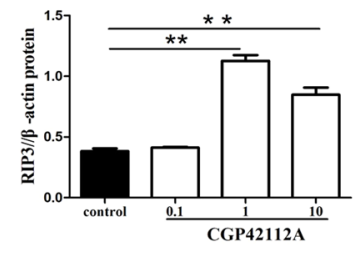

$\mathrm{E}$

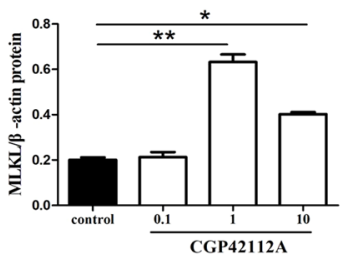

G
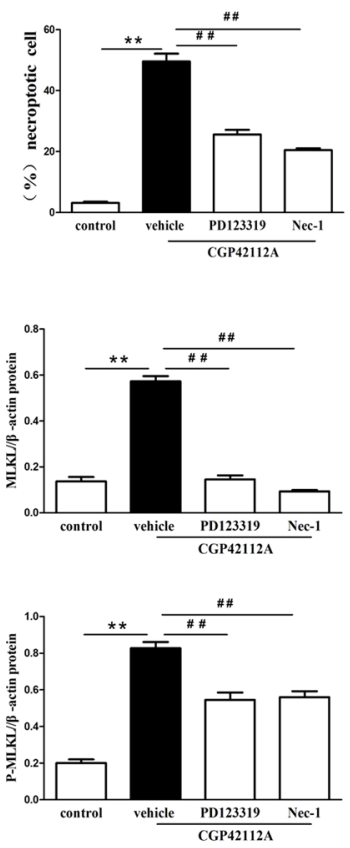

Figure 7. The AT2 agonist CGP42112A facilitates necroptosis of HK-2 cells. Effects of CGP42112A on HK-2 cells necroptosis were determined. HK-2 cells stimulated with CGP42112A at a concentration of $0,0.1,1$, and $10 \mu \mathrm{mol} / \mathrm{L}$ for $24 \mathrm{~h}$. Then, qPCR and Western Blot analysis was performed to detect the level of RIP3 and MLKL mRNA and protein (A-E). Next, HK-2 cells were pretreated with an AT2R antagonist (10 $\mu$ M PD123319) and a RIP1 inhibitor $(50 \mu \mathrm{M} \mathrm{Nec}-1)$ for $30 \mathrm{~min}$, then the cells were treated with $0.1 \mu \mathrm{M}$ CGP42112A for $24 \mathrm{~h}$. F shows representative images of immunofluorescence staining for RIP3 (red fluorescence) and in situ fluorescence TUNEL staining (green fluorescence). Scale bars represent $50 \mu \mathrm{m}$. (G) The data are presented as the $\%$ ratio of necroptotic HK-2 cells (TUNEL-positive and RIP3-positive cells). Representative blots $(\mathbf{H})$ and Western blot analysis (I) for RIP3, MLKL, p-RIP3, and p-MLKL proteins; $\beta$-actin was used as a loading control. The results shown are representative of three independent experiments. ${ }^{*} \mathrm{p}<0.05$ versus control; $* * \mathrm{p}<0.01$ versus control; ${ }^{\# \#} \mathrm{p}<0.01$ versus the CGP42112A group.

FasL significantly suppressed necroptosis in renal tubular epithelial cells and necroptosis-related proteins, suggesting that Fas/FasL, as subsequent signaling molecules of AT1R and AT2R signaling, might be involve in Ang II-induced necroptosis of renal tubular cell. 
A

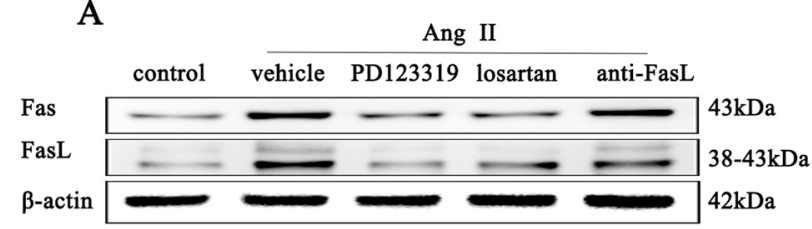

B control vehicle anti-FasL

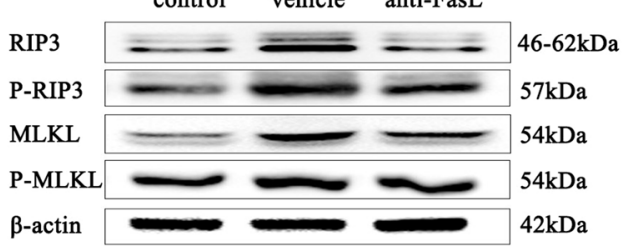

D

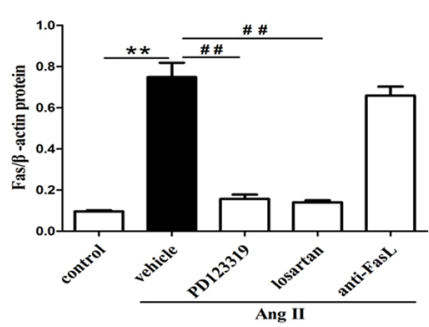

$\mathrm{F}$

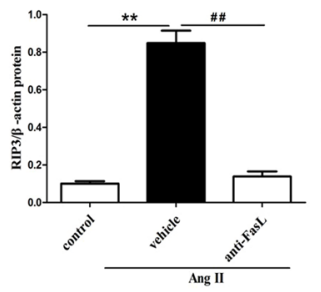

G

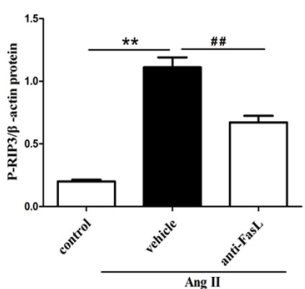

C
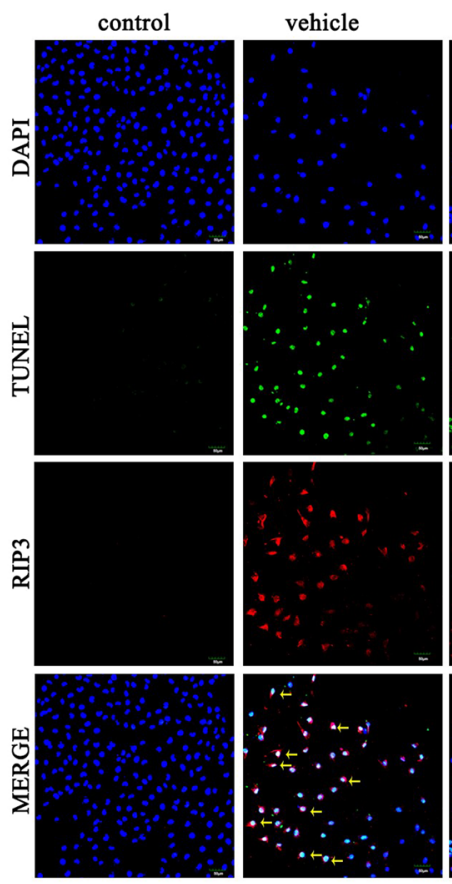

I

\section{J}
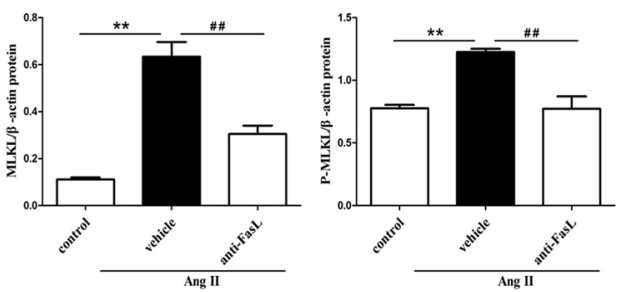

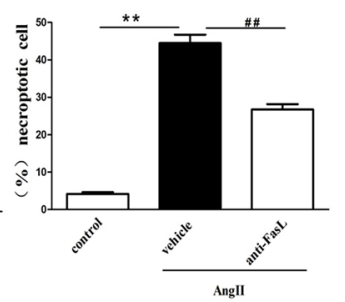

Figure 8. Inhibition of AT1R and AT2R mitigates the expression of Fas/FasL signaling molecules in Ang IIinduced HK-2 cells. Effects of FasL blockade via neutralizing human Fas ligand/TNFSF6 antibody on Ang II-induced necroptosis in HK-2 cells were determined. HK-2 cells were pretreated with $3 \mu \mathrm{g} / \mathrm{ml}$ neutralizing human Fas ligand/TNFSF6 antibody for $2 \mathrm{~h}$ and exposed to $10^{-9} \mathrm{M}$ Ang II for $24 \mathrm{~h}$. Then, Western blotting was performed to detect Fas and FasL (A,D,E), RIP3, MLKL, p-RIP3, and p-MLKL (B,F-I) levels and $\beta$-actin was used as a loading control. C shows representative images of immunofluorescence staining for RIP3 (red fluorescence) and in situ fluorescence TUNEL staining (green fluorescence). Scale bars represent $50 \mu \mathrm{m}$. (J) The data are presented as the \% ratio of necroptotic HK-2 cells (TUNEL-positive and RIP3-positive cells). The results shown are representative of three independent experiments. The intensities of the bands were determined quantitatively using Image-Pro Plus $6.0 * * \mathrm{p}<0.01$ versus control; ${ }^{\# \#} \mathrm{p}<0.01$ versus the Ang IIinduced group. Ang II: angiotensin II.

In summary, Ang II-induced necroptosis in renal tubular cells is a novel redundant mechanism of Ang II-mediated renal tubular injury and CKD, and blocking AT1R and AT2R effectively mitigates Ang II-induced increases in necroptosis of renal tubular cells. Therefore, blocking AT1R and AT2R may be a novel therapeutic approach for alleviating the excessive loss of renal tubular cells in the progression of CKD.

Received: 18 February 2019; Accepted: 24 October 2019;

Published online: 19 December 2019

\section{References}

1. White, S. L., Cass, A., Atkins, R. C. \& Chadban, S. J. Chronic kidney disease in the general population. Advances in chronic kidney disease 12, 5-13 (2005).

2. Liu, Z. H. Nephrology in china. Nature reviews. Nephrology 9, 523-528, https://doi.org/10.1038/nrneph.2013.146 (2013).

3. Erratum Regarding “US Renal Data System 2017 Annual Data Report: Epidemiology of Kidney Disease in the United States” (Am J Kidney Dis. 2018;71[3][suppl 1]:Svii,S1-S676). American journal of kidney diseases: the official journal of the National Kidney Foundation 71, 501, https://doi.org/10.1053/j.ajkd.2018.03.001 (2018). 
4. Liu, Y. Cellular and molecular mechanisms of renal fibrosis. Nature reviews. Nephrology 7, 684-696, https://doi.org/10.1038/ nrneph.2011.149 (2011).

5. Zhu, Y., Cui, H., Xia, Y. \& Gan, H. RIPK3-Mediated Necroptosis and Apoptosis Contributes to Renal Tubular Cell Progressive Loss and Chronic Kidney Disease Progression in Rats. PloS one 11, e0156729, https://doi.org/10.1371/journal.pone.0156729 (2016).

6. Gonzalez-Villalobos, R. A. et al. The absence of intrarenal ACE protects against hypertension. The Journal of clinical investigation 123, 2011-2023, https://doi.org/10.1172/jci65460 (2013).

7. Peti-Peterdi, J., Warnock, D. G. \& Bell, P. D. Angiotensin II directly stimulates ENaC activity in the cortical collecting duct via AT(1) receptors. Journal of the American Society of Nephrology: JASN 13, 1131-1135 (2002).

8. Navar, L. G., Kobori, H., Prieto, M. C. \& Gonzalez-Villalobos, R. A. Intratubular renin-angiotensin system in hypertension. Hypertension (Dallas, Tex.: 1979) 57, 355-362, https://doi.org/10.1161/hypertensionaha.110.163519 (2011).

9. Navar, L. G., Prieto, M. C., Satou, R. \& Kobori, H. Intrarenal angiotensin II and its contribution to the genesis of chronic hypertension. Current opinion in pharmacology 11, 180-186, https://doi.org/10.1016/j.coph.2011.01.009 (2011).

10. Kobori, H., Nangaku, M., Navar, L. G. \& Nishiyama, A. The intrarenal renin-angiotensin system: from physiology to the pathobiology of hypertension and kidney disease. Pharmacological reviews 59, 251-287, https://doi.org/10.1124/pr.59.3.3 (2007).

11. Lepenies, J. et al. Renal TLR4 mRNA expression correlates with inflammatory marker MCP-1 and profibrotic molecule TGF-beta(1) in patients with chronic kidney disease. Nephron. Clinical practice 119, c97-c104, https://doi.org/10.1159/000324765 (2011).

12. Siragy, H. M. Angiotensin receptor blockers: how important is selectivity? American journal of hypertension 15, 1006-1014 (2002).

13. Rodgers, K. E., Xiong, S., Steer, R. \& diZerega, G. S. Effect of angiotensin II on hematopoietic progenitor cell proliferation. Stem cells (Dayton, Ohio) 18, 287-294, https://doi.org/10.1634/stemcells.18-4-287 (2000).

14. Janke, J., Engeli, S., Gorzelniak, K., Luft, F. C. \& Sharma, A. M. Mature adipocytes inhibit in vitro differentiation of human preadipocytes via angiotensin type 1 receptors. Diabetes 51, 1699-1707 (2002).

15. Perlegas, D., Xie, H., Sinha, S., Somlyo, A. V. \& Owens, G. K. ANG II type 2 receptor regulates smooth muscle growth and force generation in late fetal mouse development. American journal of physiology. Heart and circulatory physiology 288, H96-102, https:// doi.org/10.1152/ajpheart.00620.2004 (2005).

16. Mao, C. et al. Changes of renal AT1/AT2 receptors and structures in ovine fetuses following exposure to long-term hypoxia. American journal of nephrology 31, 141-150, https://doi.org/10.1159/000259901 (2010).

17. Billet, S., Aguilar, F., Baudry, C. \& Clauser, E. Role of angiotensin II AT1 receptor activation in cardiovascular diseases. Kidney international 74, 1379-1384, https://doi.org/10.1038/ki.2008.358 (2008).

18. Shi, L., Hu, F., Morrissey, P., Yao, J. \& Xu, Z. Intravenous angiotensin induces brain c-fos expression and vasopressin release in the near-term ovine fetus. American journal of physiology. Endocrinology and metabolism 285, E1216-1222, https://doi.org/10.1152/ ajpendo.00289.2003 (2003).

19. Cui, H. et al. Necrostatin-1 treatment inhibits osteocyte necroptosis and trabecular deterioration in ovariectomized rats. Scientific reports 6, 33803, https://doi.org/10.1038/srep33803 (2016).

20. Zhu, Y. et al. Necroptosis mediated by receptor interaction protein kinase 1 and 3 aggravates chronic kidney injury of subtotal nephrectomised rats. Biochemical and biophysical research communications 461, 575-581, https://doi.org/10.1016/j.bbrc.2015.03.164 (2015).

21. Reddy, M. A. et al. Losartan reverses permissive epigenetic changes in renal glomeruli of diabetic $\mathrm{db} / \mathrm{db}$ mice. Kidney international 85, 362-373, https://doi.org/10.1038/ki.2013.387 (2014).

22. Bivalacqua, T. J., Dalal, A., Lambert, D. G., Champion, H. C. \& Kadowitz, P. J. Effects of candesartan and PD123319 on responses to angiotensin II in the anesthetized mouse. Journal of the American Society of Nephrology: JASN 10(Suppl 11), S98-100 (1999).

23. Ding, G. et al. ANG II induces c-Jun NH2-terminal kinase activation and proliferation of human mesangial cells via redox-sensitive transactivation of the EGFR. American journal of physiology. Renal physiology 293, F1889-1897, https://doi.org/10.1152/ ajprenal.00112.2007 (2007).

24. Li, X. C., Carretero, O. A., Navar, L. G. \& Zhuo, J. L. AT1 receptor-mediated accumulation of extracellular angiotensin II in proximal tubule cells: role of cytoskeleton microtubules and tyrosine phosphatases. American journal of physiology. Renal physiology 291, F375-383, https://doi.org/10.1152/ajprenal.00405.2005 (2006).

25. Mulay, S. R. et al. Cytotoxicity of crystals involves RIPK3-MLKL-mediated necroptosis. Nature communications 7, 10274, https://doi. org/10.1038/ncomms10274 (2016).

26. Kroon, A. A., Delriccio, V., Tseu, I., Kavanagh, B. P. \& Post, M. Mechanical ventilation-induced apoptosis in newborn rat lung is mediated via FasL/Fas pathway. American journal of physiology. Lung cellular and molecular physiology 305, L795-804, https://doi. org/10.1152/ajplung.00048.2013 (2013).

27. Kalivendi, S. V. et al. Doxorubicin activates nuclear factor of activated T-lymphocytes and Fas ligand transcription: role of mitochondrial reactive oxygen species and calcium. The Biochemical journal 389, 527-539, https://doi.org/10.1042/bj20050285 (2005).

28. Zhang, Z. et al. Renoprotective role of the vitamin D receptor in diabetic nephropathy. Kidney international 73, 163-171, https://doi. org/10.1038/sj.ki.5002572 (2008).

29. Kong, Y. et al. Destabilization of heterologous proteins mediated by the GSK3beta phosphorylation domain of the beta-catenin protein. Cellular physiology and biochemistry: international journal of experimental cellular physiology, biochemistry, and pharmacology 32, 1187-1199, https://doi.org/10.1159/000354518 (2013).

30. Li, Y. et al. The Calcium-Binding Protein S100A6 Accelerates Human Osteosarcoma Growth by Promoting Cell Proliferation and Inhibiting Osteogenic Differentiation. Cellular physiology and biochemistry: international journal of experimental cellular physiology, biochemistry, and pharmacology 37, 2375-2392, https://doi.org/10.1159/000438591 (2015).

31. Trichonas, G. et al. Receptor interacting protein kinases mediate retinal detachment-induced photoreceptor necrosis and compensate for inhibition of apoptosis. Proceedings of the National Academy of Sciences of the United States of America 107, 21695-21700, https://doi.org/10.1073/pnas.1009179107 (2010).

32. Grasl-Kraupp, B. et al. In situ detection of fragmented DNA (TUNEL assay) fails to discriminate among apoptosis, necrosis, and autolytic cell death: a cautionary note. Hepatology (Baltimore, Md.) 21, 1465-1468 (1995).

33. Galluzzi, L., Kepp, O. \& Kroemer, G. RIP kinases initiate programmed necrosis. Journal of molecular cell biology 1, 8-10, https://doi. org/10.1093/jmcb/mjp007 (2009).

34. Sun, L. et al. Mixed lineage kinase domain-like protein mediates necrosis signaling downstream of RIP3 kinase. Cell 148, 213-227, https://doi.org/10.1016/j.cell.2011.11.031 (2012).

35. Levey, A. S. \& Coresh, J. Chronic kidney disease. Lancet (London, England) 379, 165-180, https://doi.org/10.1016/s01406736(11)60178-5 (2012).

36. Wang, M. et al. Poricoic acid ZA, a novel RAS inhibitor, attenuates tubulo-interstitial fibrosis and podocyte injury by inhibiting TGF-beta/Smad signaling pathway. Phytomedicine: international journal of phytotherapy and phytopharmacology 36, 243-253, https://doi.org/10.1016/j.phymed.2017.10.008 (2017).

37. Sakai, N. et al. The renin-angiotensin system contributes to renal fibrosis through regulation of fibrocytes. Journal of hypertension 26, 780-790, https://doi.org/10.1097/HJH.0b013e3282f3e9e6 (2008).

38. Wang, M. et al. Novel RAS Inhibitors Poricoic Acid ZG and Poricoic Acid ZH Attenuate Renal Fibrosis via a Wnt/beta-Catenin Pathway and Targeted Phosphorylation of smad3 Signaling. Journal of agricultural and food chemistry 66, 1828-1842, https://doi. org/10.1021/acs.jafc.8b00099 (2018). 
39. Wolf, G. Cell cycle regulation in diabetic nephropathy. Kidney international. Supplement 77, S59-66 (2000).

40. Wolf, G. \& Ritz, E. Combination therapy with ACE inhibitors and angiotensin II receptor blockers to halt progression of chronic renal disease: pathophysiology and indications. Kidney international 67, 799-812, https://doi.org/10.1111/j.1523-1755.2005.00145.x (2005).

41. Feng, W. et al. Role of the transcription factor erythroblastosis virus E26 oncogen homolog-1 (ETS-1) as mediator of the renal proinflammatory and profibrotic effects of angiotensin II. Hypertension (Dallas, Tex.: 1979) 60, 1226-1233, https://doi.org/10.1161/ hypertensionaha.112.197871 (2012).

42. Bhaskaran, M. et al. Angiotensin II induces apoptosis in renal proximal tubular cells. American journal of physiology. Renal physiology 284, F955-965, https://doi.org/10.1152/ajprenal.00246.2002 (2003).

43. Cao, Z. et al. Angiotensin type 2 receptor antagonism confers renal protection in a rat model of progressive renal injury. Journal of the American Society of Nephrology: JASN 13, 1773-1787 (2002).

44. Hashimoto, N. et al. Overexpression of angiotensin type 2 receptor ameliorates glomerular injury in a mouse remnant kidney model. American journal of physiology. Renal physiology 286, F516-525, https://doi.org/10.1152/ajprenal.00294.2003 (2004).

45. Vazquez, E. et al. Angiotensin II-dependent induction of AT(2) receptor expression after renal ablation. American journal of physiology. Renal physiology 288, F207-213, https://doi.org/10.1152/ajprenal.00216.2004 (2005).

46. Namsolleck, P., Recarti, C., Foulquier, S., Steckelings, U. M. \& Unger, T. AT(2) receptor and tissue injury: therapeutic implications. Current hypertension reports 16, 416, https://doi.org/10.1007/s11906-013-0416-6 (2014).

47. Pang, X. F. et al. Attenuation of myocardial fibrosis with curcumin is mediated by modulating expression of angiotensin II AT1/AT2 receptors and ACE2 in rats. Drug design, development and therapy 9, 6043-6054, https://doi.org/10.2147/dddt.s95333 (2015).

48. Adly, A. A., Ismail, E. A., Andrawes, N. G., Mahmoud, M. M. \& Eladawy, R. Soluble Fas/FasL ratio as a marker of vasculopathy in children and adolescents with sickle cell disease. Cytokine 79, 52-58, https://doi.org/10.1016/j.cyto.2015.12.022 (2016).

\section{Acknowledgements}

The authors acknowledge Dr. Yunfeng Xia (from The First Affiliated Hospital of Chongqing Medical University, China) for technical assistance. This research was supported by grants from the National Natural Science Foundation of China (81660131 to YJZ and 81760260 to HWC) and the Natural Science Fund of Hainan Province (20168301 to YJZ and 817326 to HWC). The funding sources were not involved in the study design; in the collection, analysis and interpretation of the data; in the writing of the report; or in the decision to submit the paper for publication.

\section{Author contributions}

Y.J.Z., H.W.C. and F.Y. designed the research; J.L., S.Z.W., M.W., H.N.W. and H.W.C. performed the experiments; H.Q.L. and F.Y. analyzed the data; Y.J.Z. and Y.P.Z. assembled the figures; and Y.J.Z. and H.W.C. wrote the manuscript. All authors discussed the results and reviewed the manuscript.

\section{Competing interests}

The authors declare no competing interests.

\section{Additional information}

Correspondence and requests for materials should be addressed to Y.Z. or F.Y.

Reprints and permissions information is available at www.nature.com/reprints.

Publisher's note Springer Nature remains neutral with regard to jurisdictional claims in published maps and institutional affiliations.

(c) (i) Open Access This article is licensed under a Creative Commons Attribution 4.0 International License, which permits use, sharing, adaptation, distribution and reproduction in any medium or format, as long as you give appropriate credit to the original author(s) and the source, provide a link to the Creative Commons license, and indicate if changes were made. The images or other third party material in this article are included in the article's Creative Commons license, unless indicated otherwise in a credit line to the material. If material is not included in the article's Creative Commons license and your intended use is not permitted by statutory regulation or exceeds the permitted use, you will need to obtain permission directly from the copyright holder. To view a copy of this license, visit http://creativecommons.org/licenses/by/4.0/.

(c) The Author(s) 2019 